\title{
BIOESTIMULANTE NO VIGOR DE SEMENTES E PLÂNTULAS DE FAVEIRO (Dimorphandra mollis Benth.)
}

\author{
Ângela Canesin ${ }^{1}$, Jaqueline Maria Della Torre Martins², Silvana de Paula Quintão Scalon ${ }^{3}$, Tathiana Elisa Masetto ${ }^{4}$
}

(recebido: 5 de fevereiro de 2010; aceito: 31 de janeiro de 2012)

RESUMO: Este experimento foi desenvolvido com o objetivo de determinar os efeitos de doses de bioestimulante, aplicado via sementes, sobre o vigor de sementes e plântulas de faveiro (Dimorphandra mollis Benth.). Foram utilizadas sementes previamente escarificadas com ácido sulfúrico em experimentos realizados nos anos de 2006 e 2007. Sementes de Dimorphandra mollis, colhidas em agosto de 2006 (primeiro experimento), foram tratadas com as seguintes doses do bioestimulante Stimulate ${ }^{\circledR}$ : $0 ; 3,5 ; 7,0 ; 10,5$ e $14 \mathrm{~mL} .0,5 \mathrm{Kg}^{-1}$ de sementes; e, sementes colhidas em agosto de 2007 (segundo experimento), foram tratadas com doses de 0; 15; $20 \mathrm{e}$ $25 \mathrm{~mL} .0,5 \mathrm{Kg}^{-1}$ de sementes. Após o tratamento com o bioestimulante, as sementes foram semeadas em bandejas de células contendo latossolo vermelho distroférrico + plantmax ${ }^{\circledR}$ na proporção de 1:1 (v:v). O efeito de diferentes doses de Stimulate ${ }^{\circledR}$ em sementes de Dimorphandra mollis colhidas em diferentes anos foi avaliado por meio de porcentagem de emergência, índice de velocidade de emergência, comprimento de raiz, altura da parte aérea e massa seca de plântulas. O delineamento experimental adotado foi o inteiramente casualizado com quatro repetições de 25 sementes para cada tratamento. As doses de 14 (lote 2006 ) e $15 \mathrm{~mL} .0,5 \mathrm{Kg}^{-1}$ de sementes (lote 2007) proporcionaram maiores porcentagem de emergência (50\% e 66\%, respectivamente) e índices de velocidade de emergência ( 0,67 e 0,9 respectivamente). $\mathrm{O}$ tratamento das sementes com a dose de $20 \mathrm{~mL} .0,5 \mathrm{Kg}^{-1} \mathrm{de}$ sementes do bioestimulante favoreceu o comprimento da parte aérea, mas não influenciou os demais índices de vigor de plântulas de Dimorphandra mollis.

Palavras-chave: Cerrado, produção de mudas, fitohormônio.

\section{BIOSTIMULANT ON FAVEIRO (Dimorphandra mollis Benth.) SEEDS AND SEEDLING VIGOR}

\begin{abstract}
This work aimed to verify the effects of biostimulant doses, applied through seeds, on faveiro (Dimorphandra mollis Benth.) seeds and seedlings vigor. Seeds were previously sulfuric acid scarified in two consecutive years experiments. On 2006 August (first experiment) seeds were submitted on Stimulate ${ }^{\circledR}$ : 0; 3.5; 7.0; 10.5 and $14 \mathrm{~mL} .0 .5 \mathrm{Kg}^{-1}$ doses (first experiment); and seeds picked in August, 2007, were Stimulate:0; 15; 20 and $25 \mathrm{~mL} .0 .5 \mathrm{Kg}^{-1}$ of seeds treated (second experiment). After the biostimulant treatment seeds were sowed in cells trays containing 1:1 (v:v) distroferric red latosol + plantmax ${ }^{\circledR}$. The effect of different Stimulate ${ }^{\circledR}$ doses on Dimorphandra mollis seeds collected in different years were evaluated on the emergency percentage, speed emergency index, root length, aerial part height and dry seedling weight. It was conducted on entirely casualized with four repetitions of 25 seeds each treatment. The $14 \mathrm{~mL}$ (2006 lot) and $15 \mathrm{~mL}$ (2007 lot) $0.5 \mathrm{Kg}^{-1}$ of seeds doses provided larger percentage (50\% and $66 \%$, respectively) and speed emergency indexes ( 0.67 and 0.9 respectively). The $20 \mathrm{~mL} .0 .5 \mathrm{Kg}^{-1}$ of seeds dose treatment favored the aerial part length, but it didn't influenced the other Dimorphandra mollis seedlings vigor indexes.
\end{abstract}

Key words: Savannah, seedling production, phytohormone.

\section{INTRODUÇÃO}

A expansão agrícola, o extrativismo indiscriminado e a falta de conhecimento sobre as potencialidades são os maiores inimigos das plantas nativas do bioma Cerrado (ALMEIDA, 1998). Com a expansão da fronteira agrícola nas regiões de Cerrado, muitas plantas nativas encontramse em extinção, dentre elas o faveiro (Dimorphandra mollis Benth) (CHAVES; USBERTI, 2003), que, além disso, sofre uma alta pressão em função da coleta desordenada dos frutos para extração da rutina, substância com efeito abortivo para vacas (RIZZINI; MORS, 1976), o que tem ocasionado o corte seletivo em áreas de pecuária extensiva, contribuindo para a diminuição de indivíduos da espécie (BRANDÃO et al., 2002).

O faveiro, também conhecido como barbatimãode-folha-miúda, barbatimão-falso, canafístula ou fava d'anta, apresenta porte arbóreo que pode atingir entre

\footnotetext{
${ }^{1}$ Bióloga, Professora Doutoranda em Agronomia - Faculdade de Ciências Biológicas e Ambientais - Universidade Federal da Grande Dourados/UFGD Cx. P. 533 - Rodovia Dourados-Itahum, Km 12 - 79800-000 - Dourados, MS, Brasil - a.canesin@ufgd.edu.br

${ }^{2}$ Bióloga, Professora Mestre em Agronomia pela Universidade Federal da Grande Dourados/UFGD - Cx. P. 533 - Rodovia Dourados-Itahum, Km 12 79800-000 - Dourados, MS, Brasil - ja_que_li_ne@yahoo.com.br

${ }^{3}$ Bióloga, Professora Doutora em Ciências dos Alimentos - Faculdade de Ciências Agrárias - Universidade Federal da Grande Dourados /UFGD Cidade Universitária - Cx. P. 533 - 79804-970 - Dourados, MS, Brasil - silvana.scalon@ufgd.edu.br

${ }^{4}$ Agrônoma, Pós-Doc em Agronomia - Faculdade de Ciências Agrárias - Universidade Federal da Grande Dourados /UFGD - Cidade Universitária Cx. P. 533 - 79804-970 - Dourados, MS, Brasil - tathianamasetto@ufgd.edu.br
}

Cerne, Lavras, v. 18, n. 2, p. 309-315, abr./jun. 2012 
8 a $14 \mathrm{~m}$ de altura (PANEGASSI et al., 2000). É uma espécie nativa do Cerrado brasileiro, utilizada no paisagismo e regeneração de áreas degradadas e sua madeira pode ser empregada para tabuado, confecção de caixas, compensados, forros, painéis, brinquedos, lenha e carvão; a casca é rica em tanino, bastante utilizado em curtumes (LORENZI, 2000). Tem grande importância farmacêutica, na produção de princípios ativos constituídos por compostos fenólicos, tanino e rutina (CHAVES; USBERTI, 2003). Dos frutos são extraídos glicosídeos flavônicos, especialmente a rutina (6 a $10 \%$ ), portadora de vitamina $P$ que associada à vitamina $\mathrm{C}$, normaliza a resistência e a permeabilidade da parede dos vasos capilares do corpo humano, sendo empregada como anti-hemorrágica e complemento alimentar na dieta de idosos (SOUSA et al., 1991).

A utilização de técnicas que maximizem a produção de mudas de espécies nativas, como por exemplo, o emprego de bioestimulantes, são práticas eficientes para a produção de mudas (SCALON et al., 2009) e de fundamental importância para o estabelecimento de viveiros, por meio da diminuição do custo relativo e aumento da qualidade de mudas. Entretanto, o conhecimento sobre os aspectos ecofisiológicos e técnicas de propagação e cultivo da maioria das espécies nativas ainda são incipientes.

A literatura relata que o uso de reguladores vegetais na agricultura vem apresentando grande potencial no aumento da produtividade, uma vez que incrementa o crescimento e o desenvolvimento vegetal, estimulando a divisão celular, a diferenciação e o alongamento das células, além de aumentar a absorção e a utilização dos nutrientes (CASTRO et al., 1998). Entretanto, sua utilização ainda não é uma prática rotineira em plantas que não atingiram alto nível tecnológico, como as espécies arbóreas nativas do Cerrado.

Os biorreguladores vegetais são substâncias sintetizadas que, aplicadas exogenamente, possuem ações similares aos grupos de hormônios vegetais conhecidos como as citocininas, giberelinas, auxinas e etileno (CASTRO; VIEIRA, 2001). O Stimulate ${ }^{\circledR}$ contém 0,005\% de ácido índolbutírico (Auxina), 0,009\% de cinetina (Citocinina) e $0,005 \%$ de ácido giberélico (Giberelina) e traços de sais minerais quelatizados (STOLLER DO BRASIL, 1998). Como fitorregulador de crescimento, foi testado em diferentes regiões do Brasil com o objetivo de estudar seu efeito sobre o crescimento, o desenvolvimento e a produtividade nas culturas da soja, arroz, feijão, milho, algodão, mamona, além de frutíferas, como laranja, maracujá e videira e tem sido aplicado via sementes e por meio de pulverizações, na linha de semeadura ou foliar, em diferentes estágios dessas culturas.

Os resultados de pesquisa com tratamento de sementes com bioestimulantes são os mais diversos possíveis. Entretanto, não foram encontradas informações acerca da aplicação de fitorreguladores em sementes de Dimorphandra mollis. Dentro desse contexto, objetivouse, com este trabalho, determinar os efeitos de diferentes dosagens de Stimulate ${ }^{\circledR}$ aplicado via sementes sobre o vigor de sementes e plântulas de faveiro (Dimorphandra mollis Benth.).

\section{MATERIAL E MÉTODOS}

As sementes de Dimorphandra mollis, utilizadas para a realização do experimento, foram coletadas de 14 matrizes, espaçadas 30 metros no mínimo entre si e localizadas na Fazenda Lagoa Azul, situada à margem direita da Rodovia BR 270, Km 70, que liga Dourados a Itahum, no município de Dourados - MS, com vegetação característica de Cerrado, em agosto/2006 (Lote 2006) e em agosto/2007 (Lote 2007). A planta em estudo foi identificada pela Dra. Zefa Valdevina Pereira e as exsicatas (DDMS 1834) foram depositadas no Herbário de Dourados-MS .

Em ambos os anos, após a coleta, as vagens foram levadas ao Laboratório de Nutrição e Metabolismo de Plantas, onde foi realizada a quebra manual, seguida de extração das sementes e o beneficiamento foi realizado descartando-se as sementes mal formadas e uniformizando-as quanto ao tamanho. Os experimentos foram executados em duas etapas, em casa de vegetação e as médias de temperatura e umidade relativa no local foram de $24^{\circ} \mathrm{C}$ e $78 \%$, respectivamente, para o ano de 2006 e de $23^{\circ} \mathrm{C}$ e $75 \%$ para o ano de 2007.

Inicialmente, as sementes de Dimorphandra mollis foram escarificadas quimicamente com ácido sulfúrico concentrado (densidade 1,84), durante 30 minutos, de acordo com as recomendações de Scalon et al. (2007) para superação de dormência tegumentar e, em seguida, foram lavadas em água corrente durante dez minutos e secas até que o excesso de água fosse removido. O produto Stimulate ${ }^{\circledR}$ foi utilizado na forma líquida, dissolvido em $1 \mathrm{~mL}$ de água destilada e aplicado às sementes dispostas em placas de Petri, utilizando-se uma pipeta graduada e, em seguida, as sementes tratadas foram secas à sombra

Cerne, Lavras, v. 18, n. 2, p. 309-315, abr./jun. 2012 
durante 30 minutos. As doses utilizadas do bioestimulante Stimulate ${ }^{\circledR}$ no primeiro e segundo experimento estão descritas na Tabela 1. O aumento gradativo das doses utilizadas no experimento 2 foi determinado após as avaliações preliminares do experimento 1 .

Tabela 1 - Doses de Stimulate ${ }^{\circledR}$ (mililitros por $500 \mathrm{~g}$ de sementes).

Table 1 - Stimulate $^{\circledR}$ doses (milliter by 500 g seeds).

\begin{tabular}{lcc}
\hline \multirow{2}{*}{ Tratamentos } & \multicolumn{2}{c}{ Stimulate $^{\circledR}\left(\mathrm{mL} .0,5 \mathrm{Kg}^{-1} \mathrm{de} \mathrm{sementes}\right)$} \\
\cline { 2 - 3 } & $\begin{array}{c}\text { Experimento 1 } \\
\text { Lote 2006 }\end{array}$ & $\begin{array}{c}\text { Experimento 2 } \\
\text { Lote 2007 }\end{array}$ \\
\hline Testemunha & 0 & 0 \\
Dose 1 & 3,5 & 15 \\
Dose 2 & 7,0 & 20 \\
Dose 3 & 10,5 & 25 \\
Dose 4 & 14 & - \\
\hline
\end{tabular}

Após a secagem, as sementes tratadas foram semeadas em bandejas de isopor com 128 células preenchidas com latossolo vermelho distroférrico de textura argilosa, misturado com plantmax ${ }^{\circledR}$ na proporção de 1:1 (v:v). Para cada bandeja, em cada célula foi colocada apenas uma semente e após a emergência, 28 plântulas foram desbastadas de cada bandeja. As bandejas foram colocadas sobre as bancadas de madeira da casa de vegetação e irrigadas por aspersão uma vez por dia, até o final de 30 dias após a semeadura.

As avaliações foram realizadas durante 30 dias, registrando-se as seguintes características: porcentagem de emergência e índice de velocidade de emergência (MAGUIRE, 1962) e, ao final dos 30 dias, o vigor das plântulas foi avaliado quanto à altura da parte aérea $(\mathrm{cm})$, comprimento da raiz $(\mathrm{cm})$ e massa seca das plântulas, por meio de secagem das plântulas normais em estufa de circulação forçada sob temperatura de $65^{\circ} \mathrm{C}$, até atingirem peso constante; o peso da matéria seca de plântula foi obtido, dividindo- se o peso total das plântulas pelo número de plântulas normais.

O delineamento experimental adotado foi inteiramente casualizado, com cinco tratamentos e quatro repetições para o primeiro experimento e quatro tratamentos e quatro repetições para o segundo experimento, ambos com 25 sementes por repetição de cada tratamento. Os dados foram submetidos à análise de variância e havendo diferença significativa procedeu-se a análise de regressão para doses de Stimulate ${ }^{\circ}$ (BANZATO; KRONKA, 1992), utilizando-se programa estatístico SANEST.

\section{RESULTADOS E DISCUSSÃO}

Houve efeito significativo das doses de bioestimulante sobre a emergência de plântulas de Dimorphandra mollis. Na primeira etapa do experimento, a maior porcentagem de emergência das sementes foi observada com a aplicação da dose de $14 \mathrm{~mL}$ de Stimulate ${ }^{\circledR}$ (Figura 1), que proporcionou 50\% de emergência, correspondendo a um aumento de 1,14 vezes em relação à dose zero de Stimulate ${ }^{\circledR}$ ( $44 \%$ de emergência). Os menores resultados médios foram observados com a utilização das doses de 3,5; 7 e 10,5 mL.

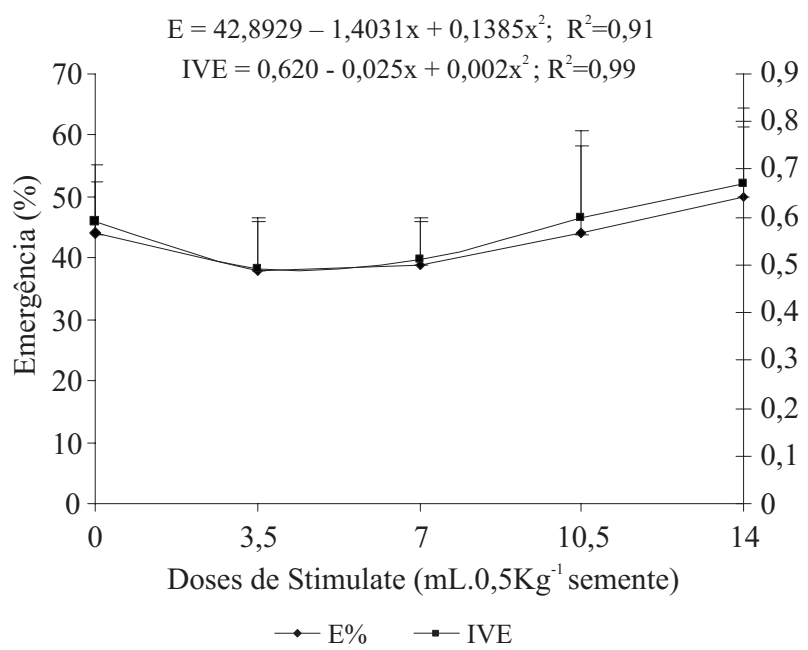

Figura 1 - Porcentagem e índice de velocidade de emergência de Dimorphandra mollis Benth. provenientes do lote 2006 aos 30 dias após a semeadura, em resposta ao tratamento das sementes com cinco doses de Stimulate ${ }^{\circledR}$.

Figure 1 - Percentage and emergency velocity index from 2006 Dimorphandra mollis seeds at 30 days after sow and five Stimulate ${ }^{\circledR}$ doses treatment.

O índice de velocidade de emergência, semelhantemente à porcentagem de emergência, também apresentou ponto de máximo estimado em 0,67 (Figura 1) com a dose de $14 \mathrm{~mL}$, totalizando um aumento de 1,14 vezes em relação ao controle e um decréscimo nos valores para as dose de 3,5; 7 e 10,5 mL.

Não foram detectadas diferenças estatísticas entre as doses de Stimulate ${ }^{\circledR}$ utilizadas no primeiro experimento em relação à altura, comprimento de raiz e massa seca das plântulas de Dimorphandra mollis, que apresentaram valores médios de $6,35 \mathrm{~cm} ; 4,24 \mathrm{~cm}$ e $0,205 \mathrm{~g}$, respectivamente.

Cerne, Lavras, v. 18, n. 2, p. 309-315, abr./jun. 2012 
No segundo experimento, a dose de $15 \mathrm{~mL}$ de Stimulate ${ }^{\circledR} .0,5 \mathrm{Kg}^{-1}$ de sementes proporcionou maior emergência de plântulas (66\%) (Figura 2). Esse resultado foi 2,6 vezes maior em relação à testemunha $(25 \%$ de emergência), e, no entanto, observou-se um decréscimo na porcentagem de emergência obtida com as doses de 20 e $25 \mathrm{~mL}$.

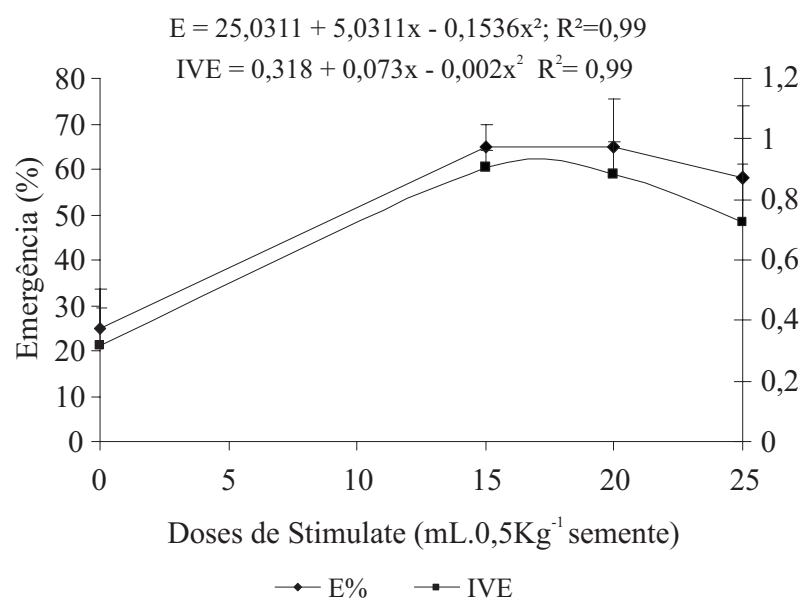

Figura 2 - Porcentagem e índice de velocidade de emergência de plântulas de Dimorphandra mollis Benth. provenientes do lote 2007 aos 30 dias após a semeadura, em resposta ao tratamento das sementes com quatro doses de Stimulate ${ }^{\circledR}$. Dourados, MS, 2009.

Figure 2 - Percentage and emergency velocity index from 2007 Dimorphandra mollis seeds at 30 days after sow and five Stimulate ${ }^{\circledR}$ doses treatment. Dourados, MS, 2009.

Semelhante à porcentagem de emergência, o índice de velocidade de emergência apresentou ponto de máxima estimado de 0,9 com a dose de $15 \mathrm{~mL}$, representando um aumento de 2,8 vezes ao obtido com o controle e um decréscimo nos valores médios obtidos com as doses de 20 e $25 \mathrm{~mL}$ do bioestimulante (Figura 2). Resultados benéficos do Stimulate ${ }^{\circledR}$ foram observados para sementes de jenipapo embebidas na solução do bioestimulante a $10 \mathrm{~mL} . \mathrm{L}^{-1}$, resultando em aumento significativo do índice de velocidade de germinação, indicando efeito positivo dessas substâncias na melhoria do desempenho germinativo das sementes (PRADO NETO et al., 2007). Os maiores resultados para a porcentagem de emergência de plântulas de maracujá azedo foram observados com as concentrações de 12 a $20 \mathrm{~mL}$ do bioestimulante/Kg de semente (FERREIRA et al., 2007).

De um modo geral, a porcentagem de emergência obtida nos dois experimentos foi baixa, provavelmente em razão das condições ambientais, fisiológicas da planta-mãe, da maturação das sementes, base genética ou do ano de coleta, conforme citado por Dores (2007). Scalon et al. (2007) avaliaram a germinação das sementes de Dimorphandra mollis coletadas na mesma região da presente pesquisa, porém, no ano de 2005, sob efeito de armazenamento, tratamentos pré-germinativos e ambiente de incubação, observaram os melhores resultados de germinação (41\%) e índice de velocidade de germinação $(4,67)$ com o pré-tratamento das sementes com ácido sulfúrico, durante 20 minutos, seguido de imersão em ácido giberélico $100 \mathrm{mg} . \mathrm{L}^{-1} 24 \mathrm{~h}$. Entretanto, Chaves e Usberti (2003) observaram uma germinação superior a $80 \%$, quando as sementes foram escarificadas mecanicamente $\mathrm{e}$ semeadas em substrato rolo de papel e incubadas a $25^{\circ} \mathrm{C}$, independente do grau de umidade da semente. Lopes e Matheus (2008) relataram a presença de tegumento duro e impermeável à água em sementes de Dimorphandra mollis, o que pode explicar o lento e desuniforme padrão de germinação apresentado pelas sementes.

De acordo com os dados do segundo experimento, além dos resultados significativos de porcentagem e índice de velocidade de emergência à aplicação do Stimulate ${ }^{\circledR}$ nas doses avaliadas (15 a $20 \mathrm{~mL} .0,5 \mathrm{Kg}^{-1}$ de sementes), observou-se, também, a ação positiva sobre o crescimento em altura da parte aérea em relação ao controle, verificado pela altura máxima das plântulas de Dimorphandra mollis com o tratamento das sementes na dose de $20 \mathrm{~mL}$ de bioestimulante, obtendo-se resultado médio de $5,83 \mathrm{~cm}$, promovendo um aumento de 1,61 vezes maior, em relação às sementes não tratadas com o bioestimulante (Figura 3). $\mathrm{O}$ bioestimulante atua como ativador da divisão das células, diferenciação e o alongamento celular, podendo também, aumentar a absorção e a utilização de água e dos nutrientes pelas plantas (STOLLER DO BRASIL, 1998).

Similar ao primeiro experimento, não houve diferenças estatísticas nos resultados médios de comprimento de raiz de plântula para as doses avaliadas de bioestimulante. As médias compreendem entre $4,1 \mathrm{~cm}$ para a dose de $25 \mathrm{~mL}$ e $4,7 \mathrm{~cm}$ para a dose de $15 \mathrm{~mL}$ (Figura 3). De acordo com Kerbauy (2004), o processo de enraizamento requer quantidades diferentes de auxinas e citocininas, dependendo da fase organogenética. Por exemplo, a fase de indução requer uma quantidade de auxina relativamente elevada, em comparação com a fase de crescimento. Na indução, a presença de auxina é um sinal para o início da divisão celular e formação do novo meristema. Entretanto, após a formação do

Cerne, Lavras, v. 18, n. 2, p. 309-315, abr./jun. 2012 


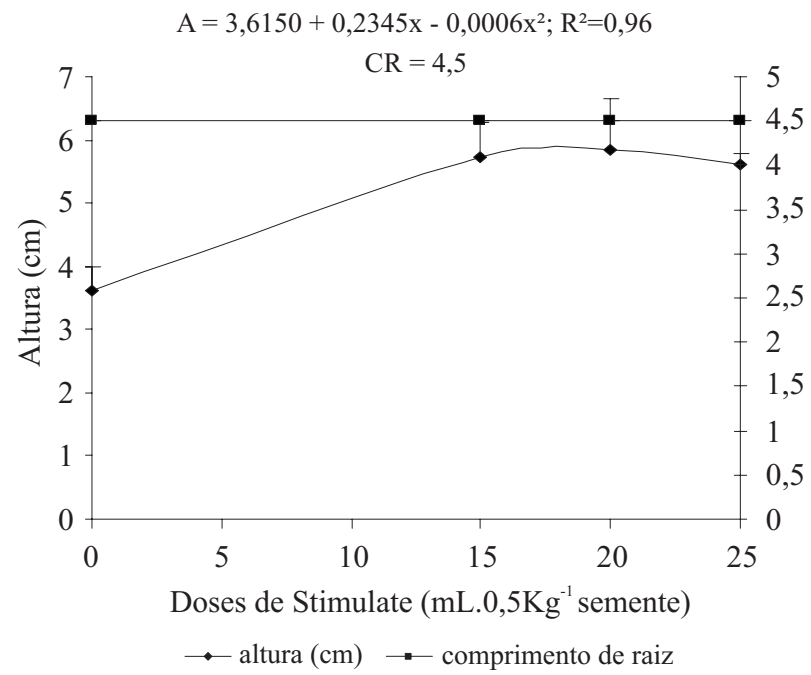

Figura 3 - Altura da parte aérea (A) e comprimento de raiz (CR) de plântulas de Dimorphandra mollis Benth. provenientes do Lote 2007 aos 30 dias após a semeadura, em resposta ao tratamento das sementes com quatro doses de Stimulate ${ }^{\circledR}$.

Figure 3 - Aerial part height and radicle length from 2007 Dimorphandra mollis seeds at 30 days after sow and four Stimulate ${ }^{\circledR}$ doses treatment.

primórdio radicular, a concentração de auxina, torna-se inibitória ao alongamento da raiz e boa parte desse efeito inibitório é mediado pela indução da produção de etileno, desencadeada pela enzima ACC sintase. Possivelmente, para a Dimorphandra mollis, o efeito do bioestimulante, em função de suas substâncias, composição e concentração, não foi suficiente para promover o crescimento das raízes.

Entretanto, os resultados obtidos tanto no primeiro e no segundo experimento com Dimorphandra mollis contrariam Marschner (1995) que relata a importância dos fitormônios auxina e citocinina como promotores do crescimento, reguladores do alongamento da raiz principal e na formação de raízes laterais das plantas. De acordo com Taiz e Zeiger (2004), as citocininas produzidas nas raízes podem induzir a formação de ramos, cujos ápices são centros produtores de auxina que, por sua vez, é necessária à formação de mais raízes. As raízes podem necessitar de uma concentração mínima de auxina para crescer, porém, seu crescimento é fortemente inibido por concentrações de auxina que promovem o alongamento de caules.

$\mathrm{O}$ efeito sobre o crescimento promovido pelo bioestimulante dependendo da dose utilizada foi comprovado em vários trabalhos. $\mathrm{O}$ uso de Stimulate ${ }^{\circledR}$ no alongamento celular de mandioquinha-salsa (Arracacia xanthorriza Bancroft) foi verificado por Reghin et al. (2000), onde o número e comprimento de raízes aumentou de acordo com o aumento da dose, até o limite de 7,0 mL.L $\mathrm{L}^{-1}$. Vieira e Castro (2001), ao avaliarem a ação do bioestimulante em sementes de soja (cv. IAC 8-2) concluíram que a concentração de $1,3 \mathrm{~mL} \cdot 0,5 \mathrm{Kg}^{-1}$ de sementes estimulou o crescimento radicular com incremento de $9,9 \%$, em relação ao controle. De acordo com os autores, o efeito do bioestimulante é mediado pela ação combinada de substâncias reguladoras do crescimento durante o processo de germinação de sementes e também, nos eventos pós- germinativos, como a mobilização de reservas.

Vieira (2001), estudando a ação do Stimulate ${ }^{\circledR}$ em sementes de arroz e feijão, constatou que o comprimento do sistema radicular foi superior em $37,7 \%$ para a dose de 2,3 $\mathrm{mL}$ do bioestimulante nas plantas de arroz e 19,8\% para a dose de $5,0 \mathrm{~mL}$ do bioestimulante. $0,5 \mathrm{Kg}^{-1}$ de sementes, no feijoeiro. Sementes do algodão cv. CNPAITA

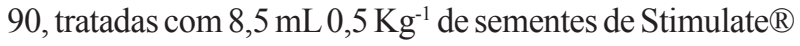
apresentaram um crescimento radicular superior em 13,6 $\%$ em relação ao controle (VIEIRA; SANTOS, 2005). Os autores consideraram que a expansão celular em tecidos de plantas é geralmente considerada como sendo regulada por hormônios, especialmente auxinas e giberelinas. Existe relativamente, pouca evidência de que tais substâncias reguladoras do crescimento funcionem como uma chave regulatória na emergência da raiz primária. Entretanto, encontra-se bem estabelecido que aplicações exógenas de certos reguladores vegetais em sementes, promovem sua germinação, estimulando a biossíntese e ação de enzimas hidrolíticas necessárias a esse processo metabólico.

O melhor resultado quanto ao comprimento de raiz de jenipapo foi observado no tratamento com Stimulate ${ }^{\circledR}$ a $10 \mathrm{~mL} . \mathrm{L}^{-1}$, cuja média superou o tratamento controle em $84,31 \%$ (PRADO NETO et al., 2007). Ferreira et al. (2007) observaram que o maior comprimento da raiz principal do maracujá azedo foram alcançados nas concentrações de 12 e $16 \mathrm{~mL}$ de bioestimulante/Kg de semente. Considerando o lento crescimento das plantas de gabiroba, Scalon et al. (2009) sugeriram que o tratamento hormonal com aplicação de bioestimulante é uma prática eficiente na produção de mudas dessa espécie.

Não foram observadas diferenças estatísticas entre as doses de bioestimulante aplicadas às sementes para a massa seca das plântulas de Dimorphandra mollis, obtendo-se média de 0,134g. Vieira (2001) observou o maior valor em relação à massa seca de raízes de feijoeiro

Cerne, Lavras, v. 18, n. 2, p. 309-315, abr./jun. 2012 
16 DAS, utilizando $5,0 \mathrm{~mL}$ de Stimulate ${ }^{\circledR} .0,5 \mathrm{Kg}^{-1}$ de sementes e incrementos significativos na massa seca total de plântulas de arroz foram observados com a utilização da dose de 5,0 mL em comparação ao controle. Prado Neto et al. (2007) constataram que a dose de $14,0 \mathrm{~mL}$ do produto. $0,5 \mathrm{Kg}^{-1}$ de sementes, promoveu um incremento na massa seca de plântulas de jenipapo de 114,7 \% em relação ao controle. De acordo com Kissman et al. (2011), mudas de carobinha-do-campo apresentaram um aumento no diâmetro do colo com a aplicação da dose de $5 \mathrm{~mL}$. $0,5 \mathrm{Kg}^{-1}$ sementes. Os autores associaram os resultados à possibilidade do bioestimulante incrementar o crescimento e desenvolvimento vegetal, estimulando a divisão celular, bem como aumentar a absorção de água e nutrientes pelas plantas.

De um modo geral, a aplicação do bioestimulante nas doses testadas em sementes de Dimorphandra mollis estimulou a emergência e altura das plântulas, mas não alterou significativamente os demais índices de vigor. Porém, como para ambas as características os melhores resultados foram obtidos com a dose de $14 \mathrm{~mL}$ do bioestimulante (primeiro experimento) e de $15 \mathrm{~mL}$ do bioestimulante (segundo experimento), provavelmente, as doses mais elevadas do produto apresentaram um efeito inibitório no alongamento celular e desenvolvimento das plântulas de Dimorphandra mollis, e as doses mais baixas não foram suficientes para estimular as reações metabólicas do embrião.

\section{CONCLUSÕES}

O tratamento com Stimulate ${ }^{\circledR}$ influencia positivamente o desempenho de sementes e o crescimento inicial de Dimorphandra mollis. As doses de $14 \mathrm{~mL}$ e $15 \mathrm{~mL}$. $0,5 \mathrm{Kg}^{-1}$, respectivamente, para os lotes de 2006 e 2007, aumentam a porcentagem e a velocidade de emergência de plântulas.

O tratamento das sementes com as doses testadas do bioestimulante não influencia no comprimento de raiz e na massa seca das plântulas de Dimorphandra mollis.

\section{AGRADECIMENTOS}

À Fundect pelo apoio financeiro.

\section{REFERÊNCIAS}

ALMEIDA, S. P. Cerrado: espécies vegetais úteis. Planaltina: Embrapa-CPAC, 1998. 464 p.

Cerne, Lavras, v. 18, n. 2, p. 309-315, abr./jun. 2012
BANZATO, D. A.; KRONKA, S. do N. Experimentação agrícola. 2. ed. Jaboticabal: FUNEP, 1992. 247 p.

BRANDÃO, M.; LACA-BUENDÍA, J. P.; MACEDO, J. F. Árvores nativas e exóticas do Estado de Minas Gerais. Belo Horizonte: Epamig, 2002.

CASTRO, P. R. C.; PACHECO, A. C.; MEDINA, C. L. Efeitos de Stimulate e de micro-citros no desenvolvimento vegetativo e na produtividade da laranjeira 'pêra' (Citrus sinensis 1. osbeck). Scientia Agrícola, Piracicaba, v. 55, n. 2, p. 338-341, 1998.

CASTRO, P. R. C.; VIEIRA, E. L. Aplicações de reguladores vegetais na agricultura tropical. Guaíba: Agropecuária, 2001.

CHAVES, M. M. F.; USBERTI, R. Prediction of Dimorphandra mollis Benth. ("Dimorphandra mollis ") seed longevity. Revista Brasileira de Botânica, São Paulo, v. 26, n. 4, p. 557-564, out./dez. 2003.

DORES, R. G. R. das. Análise morfológica e fitoquímica da fava d'anta (Dimorphandra mollis Benth.). 2007. 347 p. Tese (Doutorado em Fitotecnia) - Universidade Federal de Viçosa, Viçosa, 2007.

FERREIRA, G.; COSTA, P. N.; FERRARI, T. B.; RODRIGUES, J. D.; BRAGA, J. F.; JESUS, F. A. Emergência e desenvolvimento de plântulas de maracujazeiro azedo oriundas de sementes tratadas com bioestimulante. Revista Brasileira de Fruticultura, Jaboticabal, v. 29, n. 3, p. 595599, 2007.

KERBAUY, G. B. Fisiologia vegetal. Rio de Janeiro: Guanabara Koogan, 2004. 452 p.

KISSMANN, C.; SCALON, S. P. Q.; SCALON FILHO, H.; VIEIRA, M. C. Biorregulador e pré-condicionamento osmótico na germinação de sementes e no crescimento inicial da muda de carobinha (Jacaranda decurrens subsp. symmetrifoliolata Farias e Proença) - Bignoniaceae. Revista Brasileira de Plantas Medicinais, Botucatu, v. 13, n. 1, p. 58-67, 2011.

LOPES, J. C.; MATHEUS, M. T. Caracterização morfológica de sementes, plântulas e da germinação de Dimorphandra wilsonii Rizz. - Dimorphandra mollis -de-wilson (Fabaceae Caesalpinioideae). Revista Brasileira de Sementes, Brasília, v. 30, n. 1, p. 96-101, 2008. 
LORENZI, H. Árvores brasileiras: manual de identificação e cultivo de plantas arbóreas nativas do Brasil. Nova Odessa: Plantarum, 2000. 352 p.

MAGUIRE, J. D. Speed of germination aid in selection and evaluation for emergence and vigour. Crop Science, Madison, v. 2 , n. 2, p. 176-177, 1962.

MARSCHNER, H. Mineral nutrition of higher plants. 2. ed. San Diego: Academic, 1995. 889 p.

PANEGASSI, V. R.; SERRA, G. E.; BUCKERIDGE, M. S. Seeds of Dimorphandra mollis (Dimorphandra mollis) as a potential source of galactomannan for the food industry. Ciência, Tecnologia e Alimento, Campinas, v. 20, n. 3, 2000.

PRADO NETO, M. et al. Germinação e sementes de jenipapeiro submetidas à pré-embebição em regulador e estimulante vegetal. Ciência e Agrotecnologia, Lavras, v. 31, n. 3, p. 693-698, maio/jun. 2007.

REGHIN, M. Y.; OTTO, R. F.; SILVA, J. B. C. Stimulate ${ }^{\circledR}$ Mo e proteção com tecido não tecido no pré-enraizamento de mudas de mandioquinha-salsa. Horticultura Brasileira, Brasília, v. 18, n. 1, p. 53-56, 2000.

RIZZINI, C. T.; MORS, W. B. Botânica econômica brasileira. São Paulo: EPU/EDUSP, 1976.

SCALON, S. P. Q. et al. Potencial germinativo de sementes de Dimorphandra mollis Benth. em armazenamento, tratamentos pré-germinativos e temperatura de incubação. Cerne, Lavras, v. 13, n. 3, p. 321-328, 2007.
SCALON, S. P. Q.; LIMA, A. V.; SCALON FILHO, H.; VIEIRA, M. C. Germinação de sementes e crescimento inicial de mudas de Campomanesia adamantium camb.: efeito da lavagem, temperatura e de bioestimulantes. Revista Brasileira de Sementes, Brasília, v. 31, n. 2, p. 96103, 2009.

SOUSA, M. P. et al. Constituintes químicos ativos de plantas medicinais brasileiras. Fortaleza: UFC, 1991. 298 p.

STOLLER DO BRASIL. Stimulate ${ }^{\circledR}$ Mo em hortaliças: informativo técnico. Cosmópolis: Stoller do Brasil-Divisão Arbore, 1998.

TAIZ, L.; ZEIGER, E. Fisiologia vegetal. Porto Alegre: Artmed, 2004. 719 p.

VIEIRA, E. L. Ação de bioestimulante na germinação de sementes, vigor de plântulas, crescimento radicular e produtividade de soja (Glycine max (L.) Merrill), feijoeiro (Phaseolus vulgaris L.) e arroz (Oriza sativa L.). 2001. 122 p. Tese (Doutorado em Fitotecnia) - Escola Superior de Agricultura “Luiz de Queiroz", Piracicaba, 2001.

VIEIRA, E. L.; CASTRO, P. R. C. Ação de bioestimulante na germinação de sementes, vigor de plântulas, crescimento radicular e produtividade de soja. Revista Brasileira de Sementes, Brasília, v. 23, n. 2, p. 140-144, 2001.

VIEIRA, E. L.; SANTOS, C. M. G. Efeito de bioestimulante no crescimento e desenvolvimento inicial de plantas de algodoeiro. Magistra, Cruz das Almas, v. 17, n. 1, p. 1-8, jan./ abr. 2005.

Cerne, Lavras, v. 18, n. 2, p. 309-315, abr./jun. 2012 